\title{
Frontal Hiperhidrozda Botulinum Toksin Uygulaması
}

\section{Treatment of Frontal Hyperhidrosis With Botulinum Toxin}

\section{Ayșe Esra Koku Aksu, Zeynep Nurhan Saraçoğlu, İlham Sabuncu}

Eskișehir Osmangazi Üniversitesi Tıp Fakültesi, Deri ve Zührevi Hastalıklar Anabilim Dalı, Eskișehir, Türkiye

\section{Özet}

Fokal hiperhidroz sıklıkla aksiller ve palmoplantar bölgeye lokalizedir. Fakat daha az sıklıkla hiperhidroz alın bölgesinde de görülebilir. Hastanın yașam kalitesine olumsuz etkisi olabilir.

Otuz dört yașında erkek hasta alında terleme șikayetiyle polikliniğimiza bașvurdu. Botulinum toksin A ile tedavi edildi. Alında 30 alan ișaretlendi. Her alana $0.15 \mathrm{ml}(3 \mathrm{U})$ botulinum toksin intrakutanöz olarak injekte edildi. Hiperhidroz belirgin olarak azaldı ve bu etki 12 ay sürdü. Skindeks-29, dermatolojiye özel yașam kalite ölçeği, tedavinin bașlangıcında ve 2. haftanın sonunda hasta tarafından tamamlandı. Skindeks-29 skala ortalamalarında belirgin düzelme saptandı. Tedavi sırasında ve sonrasında yan etki saptanmadı. Botulinum toksin A tedavisi frontal hiperhidroz için etkili ve güvenli bulunmuștur. (Türkderm 201 1; 45: 161-2) Anahtar Kelimeler: Botulinum toksin A, frontal, hiperhidroz

\section{Summary}

Focal hyperhidrosis is usually localized to the axillae, palms and soles. Less frequently, hyperhidrosis may be confined to the forehead and may have negative impact on patient's quality of life.

A 34-year-old man presented to our clinic with the complaint of frontal hyperhidrosis. He was treated with botulinum toxin A. Thirty points were marked over the forehead and at each injection point, $0.15 \mathrm{ml}(3 \mathrm{U})$ botulinum toxin A were injected intracutaneously. Hyperhidrosis was significantly reduced and the effect lasted for 12 months. Skindex-29, a quality-of-life measure for skin disease, was administered to the patient at the beginning and at the end of second week of botulinum toxin A injection. There was a significant improvement on the Skindex-29 scale at the end of the treatment.

There was no any side effect detected during and after the treatment. Botulinum toxin A treatment is considered to be effective and safe for frontal hyperhidrosis. (Turkderm 2011; 45: 161-2)

Key Words: Botulinum toxin A, frontal, hyperhidrosis

\section{Giriş}

Fokal hiperhidroz sıklıkla aksiller ve palmoplantar bölgeye lokalizedir. Bazı erişkinlerde, özellikle erkeklerde, alında terleme görülebilir ve buna bağlı olarak hastanın yaşam kalitesi olumsuz yönde etkilenebilir.

\section{Olgu sunumu}

Otuz dört yaşında erkek hasta alında terleme şikayetiyle dermatoloji polikliniğine başvurdu. Hasta şikayetinin 10-12 yıldır mevcut olduğunu belirtti. Hastanın terlemesi stres, heyecan, fiziksel aktivite ve sıcakla birlikte artmaktaydı. Hasta terin gözüne damladı- 


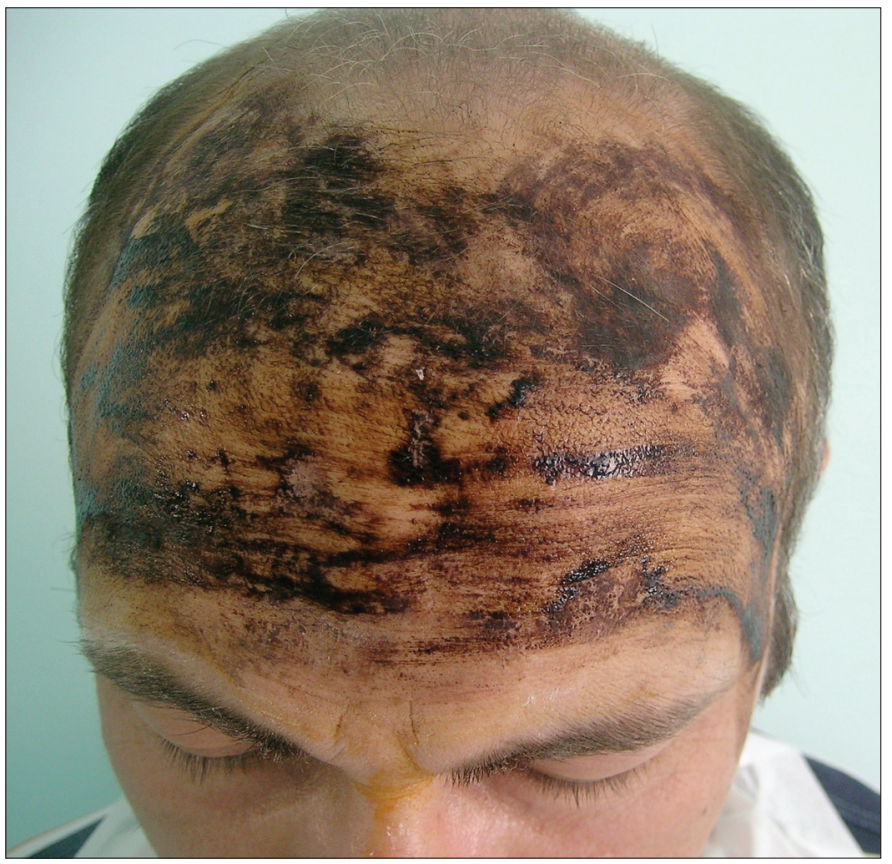

\section{Resim 1}

ğını ve görmesini etkilediğini ifade etmekteydi. Terleme için verilen lokal tedavi (\%19 alüminyum hidroksiklorid) hastanın şikayetlerini azaltmamıştı. Hastanın özgeçmişinden 2 yıl önce parsiyel tiroidektomi yapıldığı öğrenildi. Soygeçmişinde özellik saptanmadı. Hastanın laboratuvar incelemelerinde anormallik saptanmadı. Tiroid fonksiyon testleri ve kan glikoz düzeyi normal sınırlar içerisinde bulundu.

Hastadan tedavi öncesi ve sonrasında, dermatolojiye özel yaşam kalite ölçeği olan Skindeks-29'u (Türkçe uyarlamasını) tamamlaması ve ek olarak terlemesini 10 üzerinden değerlendirmesi istendi ( $0=$ terleme yok, 10 şiddetli terleme). Hastaya nişasta-iyot testi uygulandı (Resim 1). Tedavi öncesinde hastadan yazıı ınay alındı. Bir flakon botulinum toksini (100 U) $5 \mathrm{ml} \%$ 0,9 $\mathrm{NaCl}$ ile sulandırıldı. 0,15 ml solüsyonda $3 \mathrm{U}$ botulinum toksin mevcuttu. Lidokain kremle (lidokain ve prilokoin karışımı) injeksiyondan 1 saat önce uygulama yapılacak bölge kapatıldı. Terlemenin yoğun olduğu birbirinden yaklaşık 1,5 cm uzakıkta 30 alan işaretlendi. Bu işaretleme yapılırken kaş üzerinde $1 \mathrm{~cm}$ alan korundu. Her alana 0,15 ml (3U) 27G iğne ile intrakutanöz botilunim toksin A (toplam $90 \mathrm{U}$ ) injeksiyonu yapıldı. ${ }^{2}$ Hasta 2 hafta sonra nişasta-iyot testi ile değerlendirildiğinde terlemenin alında fokal bir alan dışında (\%5'ten az) tamamen gerilediği saptandı (Resim 2).

Hastanın tedavi öncesinde Skindeks-29 fonksiyon ve emosyon skala sonuçları sırasıyla 62,5 ve $65^{\prime}$ ti. Skindeks-29'da yüksek skor daha kötü yaşam kalitesini ifade eder (100 puan üzerinden değerlendirilir). Tedavi sonrasında ise fonksiyon ve emosyon skala sonuçları büyük oranda gerileyerek 12 ve 12,5'a düşmüştür. Hasta tedavi öncesinde terlemesini 10 (şiddetli terleme), tedavi sonrasında ise 2 (hafif terleme) olarak değerlendirdi. Hasta tedavi sonrasında 12 ay takip edildi. Hasta terlemesinde azalmanın 12. ayda devam ettiğini, terlemenin tedavi gerektirmeyecek düzeyde olduğunu ifade etti.

\section{Tartışma}

El ve ayak terlemesinde botulinum toksin uygulanması ile ilgili çok sayıda çalışma yapılmışken frontal hiperhidrozla ilgili sınırlı sayıda çalışma yapılmıştır. Frontal hiperhidrosisde botulinum toksin uygulanması sırasında

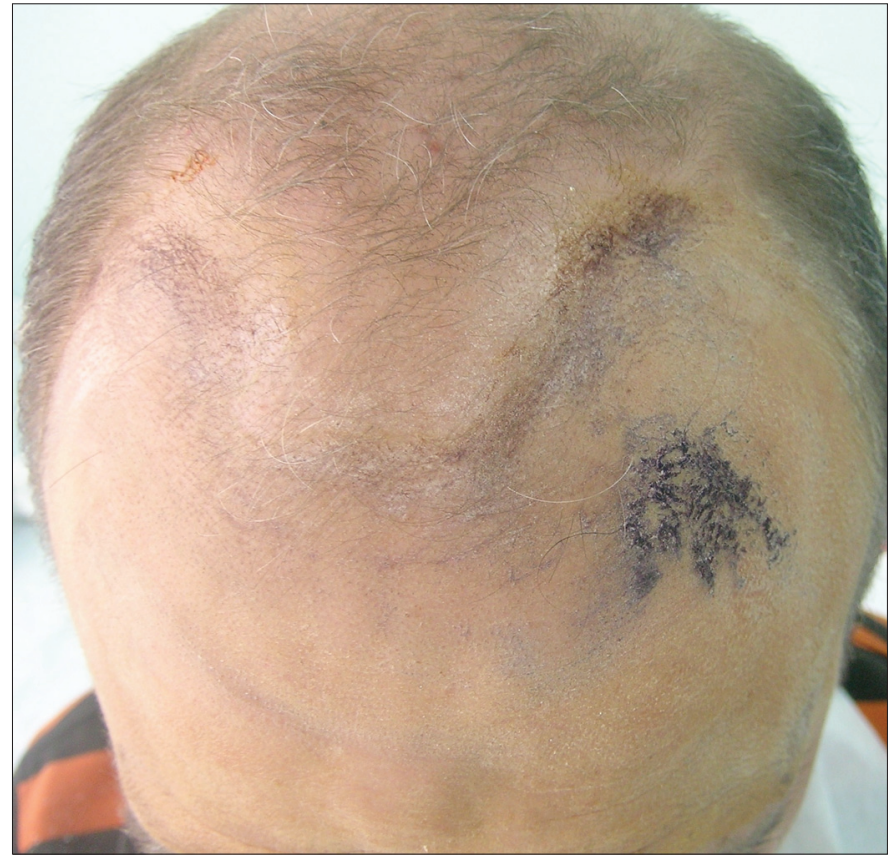

\section{Resim 2}

ağrı, sonrasında pitozis, kaş çatmada güçlük işlemin yan etkileri arasındadır. ${ }^{3}$ Pitozis yan etkisinden korunmak için uygulama sırasında kaş üzerinde $1 \mathrm{~cm}$ alanın korunması önemlidir. Kaş çatmada güçlük gelişmemesi için injeksiyon sayısının arttırılması ve injekte edilen toksin miktarının azaltıması önemlidir. Bu yan etki birkaç hafta içerisinde gerilemektedir. ${ }^{3}$ Bu uygulama sırasında ve sonrasında hastada herhangi bir yan etki saptanmadı. Botulinum toksinin hiperhidrozda etki süresi yaklaşık 4-7 aydır.,4 Hastada tedavinin etkisi ortalamanın da üzerinde, 12 ay devam etti. Fokal hiperhidrozun yaşam kalitesini olumsuz yönde etkilediği, anksiyete, depresyon ve sosyal fobiye yol açabildiği bildirilmiştir.-7 Hastamızda frontal hiperhidrozun yaşam kalitesine olan olumsuz etkisi tedavi sonrası belirgin olarak azalmıştır. Aksiller ve palmar bölgede botulinum toksin uygulaması daha yaygın olarak kullanılmaktadır. Bu olguda frontal bölgede olan hiperhidrozda da botulinum toksin uygulaması etkili ve güvenli bulunmuştur.

\section{Kaynaklar}

1. Aksu AE, Urer MS, Sabuncu I, Saracoglu ZN, Chren MM: Turkish version of Skindex-29. Int J Dermatol 2007; 46: 350-5.

2. Naumann M, Hofmann U, Bergmann I, Hamm H, Toyka KV, Reiners K: Focal hyperhidrosis: effective treatment with intracutaneous botulinum toxin. Arch Dermatol 1998;134:301-4.

3. Kinkelin I, Hund $M$, Naumann $M$, Hamm H: Effective treatment of frontal hyperhidrosis with botulinum toxin A. Br J Dermatol 2000;143:824-7.

4. Rompel R, Scholz S: Subcutaneous curettage vs. injection of botulinum toxin A for treatment of axillary hiperhidrosis. J Eur Acad Dermatol Venereol 2001;15:207-11.

5. Weber A, Heger S, Sinkgraven R et al: Psychosocial aspects of patients with focal hyperhidrosis: Marked reduction of social phobia, anxiety and depression and increased quality of life after treatment with botulinum toxin $\mathrm{A}$. $\mathrm{Br}$ J Dermatol 2005;152:342-5.

6. Tan SR, Solish N: Long-term efficacy and quality of life in the treatment of focal hyperhidrosis with botulinum toxin A. Dermatol Surg 2002;28:495-9.

7. Campanati A, Penna L, Guzzo T, Menotta L, Silvestri B, Lagalla G, Gesuita R, Offidani A: Quality-of-life assessment in patients with hyperhidrosis before and after treatment with botulinum toxin: results of an open-label study. Clin Ther 2003;25:298-308. 